\title{
The Role of Community Re-entry Program (CRP) in Strengthening the Effectiveness of Conventional Psychiatric Treatment on Therapeutic Outcomes During Hospitalization, in Patients With Schizophrenia Spectrum Disorders: a Randomized Clinical Trial
}

\section{Davood Arab Ghahestany}

Allameh Tabatabai University Faculty of Psychology and Education

Ahmad Borjali

Allameh Tabatabai University Faculty of Psychology and Education

\section{Faramarz Sohrabi}

Allameh Tabatabai University Faculty of Psychology and Education

\section{Ali Delavar}

Allameh Tabatabai University Faculty of Psychology and Education

Omid Rezaei ( $\nabla$ dromid.rezaee@gmail.com )

University of Social Welfare and Rehabilitation Science https://orcid.org/0000-0002-5832-7220

Atefeh Abbasi

University of Social Welfare and Rehabilitation Science

Fatemeh Karimi Darabi

Islamic Azad University Bandar Abbas Branch

\section{Mohammad Khorrami}

North Khorasan University of Medical Sciences

\section{Research}

Keywords: Schizophrenia, CRP, Non-pharmacological treatments, Psychosocial approaches, Therapeutic outcomes, Rehabilitation

Posted Date: May 4th, 2021

DOI: https://doi.org/10.21203/rs.3.rs-457376/v1

License: (9) (7) This work is licensed under a Creative Commons Attribution 4.0 International License. Read Full License 


\section{Abstract}

Background: Considering the many problems of conventional psychiatric therapies in the treatment of severe psychiatric disorders especially schizophrenia spectrum disorders, the aim of this study was to determine the effectiveness of CRP in the treatment of patients with schizophrenia spectrum disorders during the acute phase hospitalization of these patients.

Methods: We evaluated the role of (CRP) in strengthening the effectiveness of Conventional psychiatric treatment on the number of visits to the nursing station, PRN received, physical restraint(s) and the exact date of hospitalization and discharge of patients during hospitalization, in patients with Schizophrenia spectrum disorders. The Interventional method was Community Re-entry Program (CRP), in combination with conventional psychiatric treatment in the experimental group, while the patients in the control group received only conventional psychiatric treatment. Measurement Performed using demographic information questionnaire, and Positive and Negative syndrome Scale. Then the collected information and data were analyzed descriptively and inferentially.

Results: The results of this study showed that use of CRP in combination with conventional psychiatric treatment was more effective in reducing positive and negative syndrome, as well as the frequency of receiving PRN and physical restraint compared to conventional psychiatric treatment alone. However, the observed decrease in hospitalization duration and the rate of adhesion in the experimental group was not statistically significant.

Conclusion: These results indicate that the implementation of CRP as an adjunctive therapeutic method, can increase the effectiveness of conventional psychiatric treatment used in therapeutic centers for patients with severe psychiatric disorders, leads to better treatment outcomes for these patients, and increases the social adjustment and sustainability of these patients in society; a finding that is consistent with new therapeutic theories of these patients, experiences of expert clinicians and the findings of research on improving of therapeutic approaches to severe psychiatric disorders.

Trial registration: The study has been approved by the Ethical Review Board of the University of Social Welfare and Rehabilitation Sciences, Tehran, Iran (IR.USWR.REC.1396.150).

\section{Background}

According to research findings, psychiatric disorders are one of the most important and significant components of increasing the therapeutic burden of hospitalization centers (Haghbin et al, 2018). Among these, schizophrenia spectrum disorders are including the most severe psychiatric disorders that are very disabling in nature (American Psychiatric Association, 2020), and schizophrenia is the most severe disorder of this group that are responsible for patients most severe functional and cognitive impairments. Disorders of this diagnostic category, especially schizophrenia, often cause patients to spend most of their lives in psychiatric hospitals or to stay permanently in caring or sheltered centers. These disorders severely affect the social skills, cognition, intelligence and behavior of patients and cause a sharp decline in these areas, as a result of which patients are unable to maintain their social function and establish meaningful social relationships and are gradually excluded from society; They are also one of the most important causes of dysfunction and chronic disability around the world (Whiteford et al., 2013; Noroozi et al., 2018) and among all psychiatric disorders, they are associated with the highest socio-economic costs (Gustavson et al., 2011). The patients are not able to manage their personal affairs and follow the treatment process without supervision and support, and this problem intensifies the disorders social stigma and excludes the 
patients more and more from society (Sadock et al., 2015; Barlow \& Durand, 2015) and this is why these patients, who by themselves do not have enough insight into the disease and their need for treatment (American Psychiatric Association, 2013), rise up in defense for their self-esteem and do their best to prove to others that they are not ill; and at the same time, this method provides them with the opportunity to avoid treatment, which in turn protects them from negative and sometimes inappropriate reactions of medical staff. In this way, a negative attitude is formed towards treatment in general and hospitalization, which is associated with severe social stigma and forced acceptance of the patient's role, in particular; which, along with lack of or poor insight, act as a major obstacle in controlling signs and symptoms of the disease, and form a vicious cycle that causes the disease to worsen and increases the patients social stigma (Arab Ghahestany et al., 2018).

The clinical manifestations of schizophrenia vary from person to person and over time, but the effects of the disorder are always severe and often long-lasting. Social dysfunction is one of the most common and debilitating problems in these patients, which is common throughout the development process of schizophrenia spectrum disorders (Griffiths et al., 2021; Murphy et al., 2020; Wang et al., 2020). On the other hand, the complex nature of schizophrenia makes no single treatment approach sufficient to deal with it, and therefore psychosocial treatment approaches must be carefully integrated into the medication regimen to increasing its effectiveness (Barlow and Durand, 2015; Su et al., 2006; Sadock et al., 2015). In other words, for most patients with schizophrenia, the combined use of antipsychotic drugs and psychosocial therapies is more beneficial than the use of either of these approaches alone (Sadock et al., 2015, 2017).

Lack of social skills and decline in performance in this area is one of the prominent problems of psychiatric patients, which is manifested in patients with schizophrenia at its highest level. Naturally, one of the points that must be considered for successful treatment of these patients is the increase of social skills, which is currently considered as one of the pillars of community psychiatry and psychology and is one of the main therapeutic components in community-based interventions (Barlow and Durand, 2015; Sadock et al., 2015). In the field of such interventions, several approaches and programs have been developed, one of which is the Community Re-entry Program (CRP); A fully functional and effective collection that has resulted from decades of efforts and experiences of professor Liberman and his colleagues at UCLA; which while simple, has many practical nuances that make it superior to other approaches, especially in working with patients with schizophrenia and other severe psychiatric disorders; because on the one hand, the skills taught to patients in this program are directly focused on the weaknesses that patients face due to their disorder, weaknesses that cause all therapeutic interventions fail and the prevalence of relapse and readmission increase, and on the other hand, these educational materials is taught to patients in a simple way by using multimedia methods (including movie screening, questions and answers, lectures, assigning class and extracurricular homework and following up on them and role playing, while complying with the motivational components and with considering the scenarios related to patients daily lives at their own suggestion), which is fully commensurate with the nature of these patients' cognitive impairments; features that causing the program to be attractive and easily learnable for patients (Liberman and Silbert, 2005). Given that the promotion of mental health is one of the goals of psychotherapy in the present century (Abbasi et al., 2020; Khorrami et al., 2019), it is important for mental health professionals to teach the necessary skills to patients with schizophrenia spectrum disorders, and by this way improve their mental health and psychological well-being (Shrivastava and Sousa, 2020), and their actions in this regard are based on the results of more than two decades of controlled clinical studies by various researchers that have shown that people with schizophrenia can learn a wide range of skills (Liberman et al., 1994). 
Conventional psychiatric treatment consists of a set of therapeutic interventions including medication for all patients, some non-pharmacological treatments in a limited way (including individual and group psychological interventions, individual and group occupational therapy interventions, and individual and group social work interventions), and physiological treatments (such as electroconvulsive therapy) for a relatively wider range of patients (American Psychiatric Association, 2020). Because these approaches in the treatment of schizophrenia spectrum disorders have faced with many problems in the fields of relapse prevention and readmission reduction (Noroozi et al., 2018), control of negative syndrome, skills training, psychosocial rehabilitation, promotion of lost functions and patients preparation to discharge and facilitate the process of returning to the community, and considering that based on existing research findings, community-based interventions in general, and CRP in particular, have been successful in areas such as reducing relapse and readmission, controlling negative syndrome, improving social and behavioral skills, increasing patients' coping skills and adjustment in the community, and increasing their awareness and insight into the nature of the disease and positive attitude towards the treatment process and preparing them to discharge and facilitate the process of entering the community (Arab Ghahestany et al., 2018; Okanli et al. 2017; Armijo et al., 2013; Sato et al., 2012; Jamshidi et al., 2107a \& b), It seems that the implementation of CRP in combination with medication can enhance the effectiveness of medication, while at the same time reducing the problems of conventional psychiatric treatment and, consequently, increasing the length of stay of patients with severe psychiatric disorders in the community. Therefore, the aim of this study was to evaluate the effectiveness of CRP as a complementary therapy in comparison with conventional psychiatric treatment on patients with the most severe psychiatric disorders admitted to Raazi Psychiatric Hospital.

\section{Methods}

The study was performed in quantitative manner using a randomized clinical trial (RCT) design with pretest and posttest method and using a control group. The population of the study included all male and female patients who were admitted to the acute wards ${ }^{9}$ of Raazi Psychiatric Hospital between January 20 and March 20, 2017 with a diagnosis of at least one of the schizophrenia spectrum disorders. From these patients, a sample of 80 people was randomly selected, and assigned randomly in experimental $(n=40)$ and control $(n=40)$ groups. Inclusion criteria was included having at least one schizophrenia spectrum disorder based on the diagnosis in the medical record; absence of acute symptoms of the disorder such as aggression, hallucinations, delusions, or severe cognitive problems (such as impaired attention); having a minimum of 18 and a maximum of 65 years of age; having a family; not having comorbid personality or substance-related and addictive disorders; not having physical problems requiring special medical care; and not having the self-management skills necessary to medications and symptoms management, that assessed according to patients medical records.

Before starting the CRP, research tools were completed as a pretest for both experimental and control groups, based on medical records, observation, and patients interviews. Then, the CRP was performed in group manner with a frequency of four at least 60 minutes sessions per week on patients in the experimental group who also received conventional psychiatric treatment, while the control group received only the conventional psychiatric treatment routinely. The group sessions consisted of a maximum of 8 patients with one mentor and one assistant mentor. The titles of the sixteen sessions of the CRP and the learning activities used were:

Session 1: Introducing the CRP 
Session 2: Explaining the signs and symptoms of schizophrenia spectrum disorders according to the disorders of the patients participating in the session. (For this session, patients should have a list of their medications.)

Session 3: Determining patients' preparedness for discharge

Session 4: Planning a CRP

Session 5: Communicating with the community

Session 6: Coping with stress in the community

Session 7: Developing a daily plan

Session 8: Practicing make an appointment (visit) and do it

Session 9: How medication prevents relapse

Session 10: Evaluating the effectiveness of medication

Session 11: Solving medication problems

Session 12: Solving the problems related to the side effects of medication

Session 13: Determining the warning signs of relapse

Session 14: Following-up of relapse warning signs

Session 15: Implementing the Emergency Plan

Session 16: Bringing your plan into the community

The program was held four times a week and ended in four weeks, so that with regard to the length of stay of patients in Raazi Psychiatric Hospital (which was about a month), while not interfering with the conventional psychiatric treatment program, all of its sessions be held and completed during the patients standard hospitalization period. 
Table 1

The seven learning activities used in the CRP*

\begin{tabular}{|c|c|}
\hline Activity & Content \\
\hline Introduction & Program logic is explained to patients to motivate them to learn skills \\
\hline $\begin{array}{l}\text { Screening of the movie and } \\
\text { questions and answers about the } \\
\text { content of the film }\end{array}$ & $\begin{array}{l}\text { A movie are shown related to the desired skills, and in between, pre- } \\
\text { designed questions are asked to assess patients' understanding of what } \\
\text { was shown in the movie }\end{array}$ \\
\hline Behavioral review & Participants role play the skills they have learned \\
\hline $\begin{array}{l}\text { Solving resource management } \\
\text { problems }\end{array}$ & $\begin{array}{l}\text { Participants identify the resources needed to perform the skills by taking } \\
\text { the necessary steps to achieve them. }\end{array}$ \\
\hline $\begin{array}{l}\text { Solving problems related to } \\
\text { outcome of treatment }\end{array}$ & $\begin{array}{l}\text { Participants learn how to resolve unexpected problems by identifying } \\
\text { potential barriers, developing and evaluating alternative solutions, and } \\
\text { selecting the most effective ones. }\end{array}$ \\
\hline Objective exercises & $\begin{array}{l}\text { The mentor accompanies the participants in the field, to evaluate their } \\
\text { function in performing the skills and provide the necessary feedback. }\end{array}$ \\
\hline Homework & $\begin{array}{l}\text { Participants do their homework in a natural environment and take care of } \\
\text { it. }\end{array}$ \\
\hline
\end{tabular}

At the end of the CRP, the research tools was completed again for patients in both groups in exactly the same way as the pretest phase, and the data were recorded as posttest. The exact date of admission and discharge order by the treating psychiatrist were also extracted from the medical records of the patients. During the hospitalization periods (from the time of admission to the time of leaving the ward), the number of times patients visit the nursing station, and the number of times they received PRN ${ }^{10}$ and physical restraint ${ }^{11}$ in both groups were carefully monitored and recorded by nursing staff, and then, the mean frequency of these three variables was compared in two groups. A researcher-made questionnaire was used to collect demographic information. The research measuring tools were:

Demographic Information Questionnaire: This questionnaire was developed by the researcher with the aim of obtaining demographic information from the research sample and better describing them, and were included various variables such as gender, employment status, date of birth, approximate age of onset, marital status, income status, history of substance use, Causes of hospitalization, history of previous treatments and the patient's attitude towards them, etc.

Positive and Negative Syndrome Scale (PANSS): PANSS is a standard tool for assessing clinical outcomes in studies on the treatment of schizophrenia and other psychotic disorders and has been found to be reliably easy to perform and sensitive to therapeutic changes. Its high reliability and good coverage of positive and negative signs and symptoms make it a great tool for this purpose (Sadock et al., 2015). In the studies, the reliability of each of its scales was relatively high and the internal consistency and inter-rater reliability were reported to be excellent. Validity also seems good based on correlation with other measures of sign intensity and factor analysis validation of subscales. This scale consists of three subscales including positive (P) (with 7 axes of Delusions, Conceptual disorganization, Hallucinatory behavior, Excitement, Grandiosity, Suspiciousness/persecution, and hostility), negative (N) (with 7 axes of Blunted affect, emotional withdrawal, Poor rapport, Passive/apathetic social 
withdrawal, Difficulty in abstract thinking, Lack of spontaneity and flow of conversation, and Stereotyped thinking), and general psychopathology (G) (with 16 axes, which not used in this study). Each axis is scored in a 7 point Likert interval and the score of each subscale is composed of the sum of the scores of its axes and a higher score indicates more damage (Kay, 1991).

Scoring of research tools after implementation, and interpretation of the findings of other measurement and evaluation methods used in the study has been done by the first author of the article and in order to prevent biases in scoring tools and interpretation of the results of all measurements and evaluations, The condition was created in such a way that a person completely unaware of the logic of the study and the evaluations made in it, received the completed tools and the results of interviews and evaluations from the evaluators along with the list of patients, and hand over them to the responsible researcher without specifying that they belong to the experimental or control groups. After scoring the research tools and interpreting the findings of other measurement and evaluation methods, the same person was responsible for relating the data to the relevant patients in the experimental and control groups to prepare them for statistical analysis.

Collected data were analyzed using mean and standard deviation indices and parametric and non-parametric statistical tests including univariate analysis of covariance, Kolmogorov-Smirnov test for normalized data distribution, Levin test for homogeneity of variances, independent t-test, and univariate significance test for homogeneity of slopes.

${ }^{9}$ Acute wards are wards in which patients are admitted temporarily rather than permanently and are discharged after being treated and their symptoms controlled.

${ }^{10}$ Pro Re Nata; Intravenous or intramuscular injection of psychotropic drugs as ordered by the treating psychiatrist to calm the patient and immediately eliminate the risk in psychiatric emergency situations

${ }^{11}$ Restriction of the patient's motor activity on the order of the treating psychiatrist because he/she is threatening or dangerous to him/herself or others

\section{Results}

10 percent (4 participants) of participants in the experimental group was excluded from the study before the end of the CRP due to discharge by the treating psychiatrist. Attrition rate in the control group was 17.5 percent ( 7 participants) due to discharge with personal consent or discharge by the treating psychiatrist. None of the experimental group participants requested to leave the study before the end of the CRP.

The results of the demographic data analysis of the participants in the experimental and control groups indicated that most of the patients in both groups were male, unemployed, incomeless and single, with high school education level. Symptoms first appeared around the age of 25. They had been hospitalized at least once. All of them had a family history of psychiatric disorder and no previous history of non-pharmacological treatment, all of which were among the poor prognosis factors. The findings derived from analysis of experimental and control groups demographic data are listed in Tables 2 and 3. 
Table 2

Information of demographic variables other than age and age of disease onset in experimental and control groups

\begin{tabular}{|c|c|c|c|c|c|}
\hline \multirow[t]{2}{*}{ Variables } & & \multicolumn{2}{|l|}{ Frequency } & \multicolumn{2}{|l|}{ Percent } \\
\hline & & Experimental & Control & Experimental & Control \\
\hline \multirow[t]{3}{*}{ Gender } & Male & 23 & 23 & 63.9 & 69.7 \\
\hline & Female & 13 & 10 & 36.1 & 30.3 \\
\hline & Total & 36 & 33 & 100 & 100 \\
\hline \multirow[t]{3}{*}{ Employment status } & Employed & 3 & 3 & 8.3 & 9.1 \\
\hline & Unemployed & 33 & 30 & 91.7 & 90.9 \\
\hline & Total & 36 & 33 & 100 & 100 \\
\hline \multirow[t]{3}{*}{ Have income } & Yes & 5 & 6 & 13.9 & 18.2 \\
\hline & No & 31 & 27 & 86.1 & 81.8 \\
\hline & Total & 36 & 33 & 100 & 100 \\
\hline \multirow[t]{5}{*}{ Marital status } & Single & 14 & 15 & 38.9 & 45.5 \\
\hline & Married & 8 & 9 & 22.2 & 27.3 \\
\hline & Separated & 8 & 4 & 22.2 & 12.1 \\
\hline & Divorced & 6 & 5 & 16.7 & 15.2 \\
\hline & Total & 36 & 33 & 100 & 100 \\
\hline \multirow[t]{4}{*}{ Educatin level } & Illiterate & 3 & 1 & 8.3 & 3.0 \\
\hline & High school & 23 & 27 & 63.9 & 81.8 \\
\hline & College & 10 & 5 & 27.8 & 15.2 \\
\hline & Total & 36 & 33 & 100 & 100 \\
\hline \multirow[t]{3}{*}{ Hospitalization history } & Yes & 32 & 88.9 & 29 & 87.9 \\
\hline & No & 4 & 11.1 & 4 & 12.1 \\
\hline & Total & 36 & 100 & 33 & 100 \\
\hline \multirow{3}{*}{$\begin{array}{l}\text { Family history of psychiatric } \\
\text { disorder }\end{array}$} & Yes & 24 & 66.7 & 23 & 69.7 \\
\hline & No & 12 & 33.3 & 10 & 30.3 \\
\hline & Total & 36 & 100 & 33 & 100 \\
\hline \multirow[t]{4}{*}{ Number of hospitalizations } & $\begin{array}{l}\text { No hospitalization } \\
\text { history }\end{array}$ & 4 & 4 & 11.1 & 12 \\
\hline & Once & 4 & 2 & 11.1 & 6.1 \\
\hline & Twice & 5 & 2 & 13.9 & 6.1 \\
\hline & 3 times & 4 & 5 & 11.1 & 15.2 \\
\hline
\end{tabular}




\begin{tabular}{|llllll|} 
& 4 times & 3 & 3 & 8.3 & 9.1 \\
\cline { 2 - 6 } & 5 times & 1 & 0.0 & 2.8 & 0.0 \\
\hline +5 times & 15 & 17 & 41.7 & 51.5 \\
\hline Family support & Total & 32 & 29 & 100 & 100 \\
& Yes & 24 & 66.7 & 22 & 66.7 \\
\cline { 2 - 6 } & No & 12 & 33.3 & 11 & 33.3 \\
\hline $\begin{array}{l}\text { Previous history of non- } \\
\text { pharmacological treatments }\end{array}$ & Total & 36 & 100 & 33 & 100 \\
& Yes & 5 & 13.9 & 6 & 18.2 \\
\cline { 2 - 6 } & No & 31 & 86.1 & 27 & 81.8 \\
\cline { 2 - 5 } & Total & 36 & 100 & 33 & 100 \\
\hline
\end{tabular}

Table 3

Information of demographic variables of age and age of disease onset in experimental and control groups

\begin{tabular}{|lllllll|}
\hline Variables & & Mean & Standard deviation & Range & Min & Max \\
\hline Experimental & Age & 37.83 & 9.437 & 40 & 20 & 60 \\
Control & & 39.73 & 10.372 & 37 & 20 & 57 \\
Experimental & Age of disease onset & 36.03 & 5.754 & 22 & 18 & 40 \\
Control & & 28.79 & 7.709 & 26 & 19 & 45 \\
\hline
\end{tabular}

Below, we describe the descriptive data of the research variables in Table 4: 
Table 4

Mean and standard deviation of research dependent variables in the experimental and control groups

\begin{tabular}{|c|c|c|c|c|}
\hline CRP & & & Pre-test & Post-test \\
\hline \multirow[t]{8}{*}{ Positive syndrome } & \multirow[t]{4}{*}{ Experimental } & Mean & 24.86 & 12.11 \\
\hline & & Standard deviation & 5.876 & 2.984 \\
\hline & & Min & 13 & 8 \\
\hline & & Max & 37 & 19 \\
\hline & \multirow[t]{4}{*}{ Control } & Mean & 26.76 & 14.27 \\
\hline & & Standard deviation & 5.483 & 2.875 \\
\hline & & Min & 16 & 9 \\
\hline & & Max & 36 & 22 \\
\hline \multirow[t]{8}{*}{ Negative syndrome } & \multirow[t]{4}{*}{ Experimental } & Mean & 25.78 & 13.44 \\
\hline & & Standard deviation & 6.034 & 3.308 \\
\hline & & Min & 14 & 7 \\
\hline & & Max & 36 & 20 \\
\hline & \multirow[t]{4}{*}{ Control } & Mean & 29.52 & 24.67 \\
\hline & & Standard deviation & 4.982 & 4.378 \\
\hline & & Min & 19 & 12 \\
\hline & & Max & 40 & 36 \\
\hline \multirow[t]{8}{*}{ Adhesion } & \multirow[t]{4}{*}{ Experimental } & Mean & 2.44 & \\
\hline & & Standard deviation & 2.772 & \\
\hline & & Min & 0 & \\
\hline & & Max & 10 & \\
\hline & \multirow[t]{4}{*}{ Control } & Mean & 2.94 & \\
\hline & & Standard deviation & 3.499 & \\
\hline & & Min & 0 & \\
\hline & & Max & 11 & \\
\hline \multirow[t]{5}{*}{ Number of PRN received } & \multirow[t]{4}{*}{ Experimental } & Mean & 2.56 & \\
\hline & & Standard deviation & 1.858 & \\
\hline & & Min & 0 & \\
\hline & & Max & 8 & \\
\hline & Control & Mean & 4.06 & \\
\hline
\end{tabular}




\begin{tabular}{|c|c|c|c|c|}
\hline \multicolumn{3}{|l|}{ CRP } & \multirow{2}{*}{$\begin{array}{l}\text { Pre-test } \\
2.207\end{array}$} & \multirow[t]{2}{*}{ Post-test } \\
\hline & & Standard deviation & & \\
\hline & & Min & 0 & \\
\hline & & Max & 10 & \\
\hline \multirow[t]{8}{*}{ Number of physical restraint received } & \multirow[t]{4}{*}{ Experimental } & Mean & 0.86 & \\
\hline & & Standard deviation & 1.199 & \\
\hline & & Min & 0 & \\
\hline & & Max & 4 & \\
\hline & \multirow[t]{4}{*}{ Control } & Mean & 1.70 & \\
\hline & & Standard deviation & 2.099 & \\
\hline & & Min & 0 & \\
\hline & & Max & 10 & \\
\hline \multirow[t]{8}{*}{ Duration of hospitalization } & \multirow[t]{4}{*}{ Experimental } & Mean & 32.17 & \\
\hline & & Standard deviation & 2.408 & \\
\hline & & Min & 28 & \\
\hline & & Max & 37 & \\
\hline & \multirow[t]{4}{*}{ Control } & Mean & 32.00 & \\
\hline & & Standard deviation & 2.716 & \\
\hline & & Min & 25 & \\
\hline & & Max & 37 & \\
\hline
\end{tabular}

With a closer look at the findings in the above table, it can be seen that the mean of the experimental group (simultaneous implementation of conventional psychiatric treatment and CRP) was superior to the mean of the control group in all variables except the duration of hospitalization.

Then, in order to evaluate the effectiveness of the CRP on the treatment variables of positive and negative syndrome and with the aim of controlling the effect of the pretest, the analysis of covariance was used; the results of which are presented in Table 5. Since the use of analysis of covariance requires the observance of some basic assumptions including the normality of the distribution of dependent variable data, homogeneity of variances and homogeneity of the slope of regression lines, the Kolmogorov-Smirnov test was used to check the normality of data distribution (positive syndrome, $z=0.671$ and $p=0.761$ and negative syndrome, $z=0.091$ and $p=0.189$; which due to the non-significance of $z$ value of the test, it was concluded that the distribution of scores in these variables is normal), Levin test was used to examine the homogeneity of variances (positive syndrome, $F=0.540$ and $p=0.380$ and negative syndrome $F=0.06$ and $p=3.89$; which due to the non-significance of $F$ value of the test, The assumption of homogeneity of variances was established), and a univariate significance test was used to examine the homogeneity of slopes (positive syndrome, $F=0.04$ and $p=0.849$ and negative syndrome, $F=9.15$ 
and $p=0.004$; which due to the non-significance of $F$ value of the test, The assumption of homogeneity of slopes was established regarding the positive syndrome variable). In the case of negative syndrome variable, despite the fact that the assumption of homogeneity of slopes was not established, due to the establishment of other assumptions at the 99 percent confidence level, the analysis of covariance was used cautiously.

Table 5

Results of univariate analysis of covariance for therapeutic variables of positive and negative syndrome

\begin{tabular}{|c|c|c|c|c|c|c|c|}
\hline Variables & Effect & SS & $\begin{array}{l}\text { Degr. of } \\
\text { freedom }\end{array}$ & MS & $F$ & p & $\begin{array}{l}\text { Partial eta- } \\
\text { squared }\end{array}$ \\
\hline \multirow{4}{*}{$\begin{array}{l}\text { Positive } \\
\text { syndrome }\end{array}$} & Intercept & 14.67 & 1 & 14.67 & 5.37 & .024 & 0.075 \\
\hline & $\begin{array}{l}\text { Po. Syndrome } \\
\text { pretest }\end{array}$ & 395.71 & 1 & 395.71 & 144.78 & .000 & 0.687 \\
\hline & Group CRP & 30.59 & 1 & 30.59 & 11.19 & .001 & 0.145 \\
\hline & Error & 180.39 & 66 & 2.73 & & & \\
\hline \multirow{4}{*}{$\begin{array}{l}\text { Negative } \\
\text { syndrome }\end{array}$} & Intercept & 23.23 & 1 & 23.23 & 5.15 & .026 & 0.072 \\
\hline & $\begin{array}{l}\text { Ne. Syndrome } \\
\text { pretest }\end{array}$ & 698.75 & 1 & 698.75 & 155.03 & .000 & 0.701 \\
\hline & Group CRP & 1263.27 & 1 & 1263.27 & 280.28 & .000 & 0.809 \\
\hline & Error & 297.47 & 66 & 4.51 & & & \\
\hline
\end{tabular}

The data in Table 5 show that the result of univariate covariance test was significant for the positive and negative syndrome variables at the 99 percent confidence level $(P<0.01)$. Respectively (partial eta-square $=0.145, p=0.001$, $\left.F_{(1,66)}=11 / 19\right)$ and (partial eta-square $\left.=0.809, p=0.001, F_{(1,66)}=280.28\right)$. Therefore, it can be concluded that due to the implementation of the independent variable, there was a significant difference in the severity of positive and negative symptoms between the experimental and control groups (by modulating the effect of the pretest). In other words, it can be said that the CRP has been able to significantly reduce the positive and negative syndrome in the experimental group compared to the control group.

The significance of the effectiveness of CRP on the treatment variables of frequency of physical restraint and PRN, adhesion rate, and duration of hospitalization was assessed by Student's t-test, which required checking the homogeneity of variance using Levin test. The results are listed in Table 6. 
Table 6

Results of independent Student's t-test for therapeutic variables of physical inhibition, PRN, adhesion, and duration of hospitalization

\begin{tabular}{|c|c|c|c|c|c|c|c|c|c|c|c|}
\hline \multirow[t]{2}{*}{ Variable } & \multicolumn{3}{|c|}{ Experimental } & \multicolumn{3}{|c|}{ Control } & \multicolumn{2}{|c|}{$\begin{array}{l}\text { Homogeneity } \\
\text { of variance } \\
\text { assumption } \\
\text { (Levin test) }\end{array}$} & \multicolumn{3}{|c|}{$\begin{array}{l}\text { Independent t-test of } \\
\text { significance }\end{array}$} \\
\hline & Mean & SD. & No. & Mean & SD. & No. & $\begin{array}{l}\text { Sig. } \\
\text { level }\end{array}$ & $\begin{array}{l}\mathbf{F} \\
\text { ratio }\end{array}$ & $\begin{array}{l}\text { Sig. } \\
\text { level }\end{array}$ & $\begin{array}{l}\text { Degr. of } \\
\text { freedom }\end{array}$ & $\begin{array}{l}\mathrm{t} \\
\text { value }\end{array}$ \\
\hline $\begin{array}{l}\text { Physical } \\
\text { restraint }\end{array}$ & 0.86 & 1.20 & 36 & 1.70 & 2.10 & 33 & 0.024 & 5.27 & 0.049 & 49.92 & -2.007 \\
\hline PRN & 2.56 & 1.85 & 36 & 4.06 & 2.21 & 33 & 0.392 & 0.74 & 0.003 & 67 & -3.072 \\
\hline Adhesion & 2.44 & 2.77 & 36 & 2.94 & 3.50 & 33 & 0.065 & 3.51 & 0.515 & 67 & -0.654 \\
\hline $\begin{array}{l}\text { Duration of } \\
\text { hospitalization }\end{array}$ & 32.17 & 2.41 & 36 & 32.00 & 2.72 & 33 & 0.888 & 0.020 & 0.788 & 67 & 0.270 \\
\hline
\end{tabular}

The data in Table 6 show that the result of independent Student's t-test for therapeutic variables of frequency of PRN and physical inhibition was significant, respectively, at 99 and 95 percent confidence levels $(p<0.01$ and $p<$ 0.05); Of course, considering that based on the results of Levin test, the assumption of homogeneity of variances was not established for the variable of physical restraint frequency $(F=5.27$ and $p=0.024)$, Welch correction was used to test the significance of the variable findings. In other words, it can be said that the CRP has been able to significantly reduce the frequency of PRN and physical restraint in patients of the experimental group. However, regarding the variables of adhesion ${ }^{12}$ and duration of hospitalization, the results of independent Student's t-test ( $F$ $=3.51, p=0.065$ and $F=0.02, p=0.888$ ) indicated that the CRP could not cause a significant decrease in the amount of these two variables.

${ }^{12}$ Multiple visits with the same content to the nursing station

\section{Discussion}

The aim of the study was to evaluate the effectiveness of CRP on therapeutic variables during hospitalization period in patients with schizophrenia spectrum disorders and compare it with conventional psychiatric treatment of these patients in Raazi Psychiatric Hospital. In general, the results showed that compared with conventional psychiatric treatment of patients with schizophrenia spectrum disorders, the simultaneous implementation of conventional psychiatric treatment and CRP was more effective on the therapeutic outcomes during hospitalization period. The findings are consistent with the results of previous studies in the field (Arab Ghahestany et al., 2018; Okanli et al., 2017; Jamshidi et al., 2017a; Xiang et al., 2007; Liberman et al., 1998).

A closer look at the results of this study showed that as a result of incorporating the CRP into conventional psychiatric treatment, there was a significant difference between experimental and control groups in the variables of positive and negative syndrome (by modulating the effect of the pre-test) and the two variables of PRN and physical restraint frequency, meaning that patients who participated in CRP in addition to conventional psychiatric treatment showed a greater reduction in the above variables than patients who received only conventional psychiatric treatment. But despite the observed difference in the mean scores of variables of adhesion and 
duration of hospitalization in the two groups, these differences were not significant. In the following, we explain each of these findings, respectively.

The results showed that there was a difference in the positive syndrome variable between the participants of the experimental and control groups, that although was not large, but even this small difference was significant. In this regard, it should be noted that the signs and symptoms classified under the label of positive syndrome are inherently among the ones that are rightly the subject of medication, and at least in our country there is little reliance on the use of non-pharmacological strategies to treat them (Arab Ghahestany et al., 2018). It is also not expected that non-pharmacological approaches, especially approaches based on psychoeducation, can be effective in controlling these signs and symptoms that are characteristic of schizophrenia and other severe psychiatric disorders and are among the most troublesome psychiatric signs and symptoms (Jamshidi et al. 2017b). However, this finding clearly shows that even in the control and treatment of signs and symptoms that have long been the subject of medication, the effectiveness of non-pharmacological treatment approaches should not be overlooked, because despite the success of medication in controlling positive syndrome and its significant effectiveness in this context, incorporating non-pharmacological approaches such as CRP into pharmacological approaches can be effective in strengthening the effectiveness of these approaches, and further reduces the positive syndrome, which in turn play a role in improving the treatment outcome and controlling the disease faster and more effectively; because such an intervention is effective in increasing patients' information and improves their therapeutic attitude and adherence (Arab Ghahestany et al., 2018). Given the fact that the effectiveness of the CRP on this dependent variable has been confirmed in many studies (the findings of Armijo et al., 2013; Xiang et al., 2007; Xiang et al., 2006; Anzai et al., 2002 And Jamshidi et al., 2017a, on the effectiveness of CRP on reducing positive syndrome; and the findings of Granholm et al., 2005 and Bastillo et al., 2001, on the effectiveness of psychosocial therapies on reducing these symptoms); lack of effectiveness confirmation of the intervention program on positive syndrome in a few studies conducted in our country (Jamshidi et al., 2017b; and Mohammadzadeh Nanehkaran et al., 2013), can be due to reasons such as methodological problems, difficulty in correct implementation of the CRP, and also the research samples differences.

The therapeutic variable of negative syndrome also decreased more in the experimental group compared to the control group, but the importance of the finding becomes more when we consider that the negative syndrome is not much affected by medication (Armijo et al., 2013). In other words, medication is not an appropriate therapeutic approach to reduce the negative signs and symptoms, and this point can be well seen in the observed difference in the scores of negative syndrome in the experimental and control groups. Given that negative symptoms are mainly related to loss of skills and decline in function (Gale, 2008), it is not unreasonable to expect that medication can have little effect on reducing them because, skill training and performance improvement are in the area of rehabilitation, that is outside the scope of pharmacotherapy and addressing it requires the use of nonpharmacological interventions, and for this reason, the implementation of the CRP has been able to cause such a difference in this variable, and like many studies in the field (Armijo et al., 2013; Xiang et al., 2007; Xiang et al., 2006; Anzai et al., 2002; Jamshidi et al., 2017b; and Mohammadzadeh Nanehkaran et al., 2013, on the effectiveness of CRP in reducing negative syndrome; and Bastillo et al., 2001, on the effectiveness of psychosocial therapies on reducing these symptoms), emphasizes the need to complement medication with nonpharmacological therapies such as CRP. Reducing negative syndrome increases quality of life and personal function, improves social and interpersonal relationships, and increases self-management, which in turn improves treatment outcomes and increases the patient's ability to remain in the community and is therefore, one of the most important therapeutic goals. 
Regarding the variable of PRN frequency, a significant positive effect was observed as a result of implementing the CRP. In other words, the difference between the participants in the experimental and control groups in terms of the number of times they received PRN was significant and showed that patients who participated in the CRP in addition to conventional psychiatric treatment, were in a much better position in this regard than patients who received only conventional psychiatric treatment, regarding the observed difference in the mean number of times they received PRN (2.56 in the experimental group vs. 4.06 in the control group). A very important and new finding in this study.

Implementation of CRP also showed a positive and significant effect on reducing the frequency of physical restraint. In other words, the difference between the participants in the experimental and control groups in terms of the number of times they received physical restraint was significant and showed that patients who participated in CRP in conjunction with conventional psychiatric treatment were much better in this regard than patients who received only conventional psychiatric treatment, regarding the observed difference in the mean number of times they were physically restrained ( 0.86 in the experimental group vs. 1.70 in the control group). This point was also an important and new finding in this study.

PRN and physical restraint, by their definitions (Sadock et al., 2015) are invasive interventions that are carried out forcefully and against the patient's will, and as a result can have a negative impact on patients' attitudes toward treatment and hospitalization, as well as their participation and cooperation in the treatment process (this effect is more severe in the case of physical restraint) (Arab Ghahestany et al., 2018). But the important point to note is that, unlike medication, which is a necessary therapeutic intervention, the nature of these controlling therapeutic interventions is such that the conditions can be provided in such a way that there is no need to administrate them. In other words, to eliminate their necessity, the emergence of psychiatric emergencies must be prevented. Conventional psychiatric treatment can prevent many of these emergency situations that caused by disorder's symptoms (mainly positive symptoms and other psychological factors). although psychosocial treatment approaches have also a proven effect on many of these symptoms, including delusions, mood and anxiety problems, etc., Abbasi et al., 2019, 2020; Armijo et al., 2013). However, some of these situations occur as a result of negative symptoms or, in better words, lack of skills; which, as mentioned earlier, can't prevented using conventional psychiatric treatment, and this is the reason for the significant difference observed in this part of the present study. Therefore, to compensate for the weakness, it is necessary to complement conventional psychiatric approaches using non-pharmacological approaches, such as CRP, in which, the skill training aspect is highly emphasized.

Therefore, the findings of this part of the study clearly show that the implementation of non-pharmacological treatment approaches such as CRP can well cover the weakness of medications in reducing the incidence of situations that necessitate invasive interventions such as PRN and physical restraint for patients, and highly reduce the frequency of such interventions, that have a negative impact on the patients treatment process and their relationship with the treatment staff and cause a negative attitude in them toward treatment and reduce their cooperation in the process, as well as, emphasize the need to complement medication with non-pharmacological treatment approaches.

Based on the findings of the study, the implementation of CRP could not have a significant effect on duration of hospitalization and adhesion rate, and there was no significant difference in these two variables between the experimental and control groups. This finding was inconsistent with findings of Armijo et al. (2013) on the effectiveness of community-based interventions on reducing duration of hospitalization.

Page $15 / 20$ 
But what could be the probable cause of the finding? At first glance, it seems that the implementation of the CRP could not reduce the duration of hospitalization, but if we look more closely at the issue, considering the other variables studied in this study, such as positive and negative syndrome and frequency of PRN and physical restraint, It is clear that, in fact, patients are usually and conventionally discharged very early, before their symptoms are fully controlled and become ready to be discharged, which causes their disorder to relapse very quickly and be re-admitted to the hospital. However, if the patients' discharge time, or more accurately, the goal of their treatment, is determined realistically, and patients who are receiving conventional psychiatric treatment are discharged when they become equally recovered and controlled as patients who are receiving complementary CRP, then their duration of hospitalization becomes much more longer, and even may never reach the level of recovery needed for discharge and remain in the hospital permanently.

Regarding the frequency of adhesion, considering that the adhesion mean score of the participants in the experimental and control groups was different (2.44 vs. 2.94) but the difference was not significant, it can be concluded that the effect of CRP on the adhesion rate was likely a delayed one, in the sense that it appeared gradually and after a period of time from the start of treatment, and perhaps if, based on what was said about the duration of hospitalization, the time of discharge in the conventional psychiatric treatment group was realistic, the difference would increase and reach a significant level, although even now it has made a difference of about 17 percent. But this conclusion is purely probabilistic and should be considered in future research.

Therefore, if we look at the findings of this part of the study from this point of view, we will see that the implementation of CRP has reduced the length of hospitalization needed to improve patients with schizophrenia and therefore, it can be clearly claimed that incorporating non-pharmacological therapeutic approaches in conventional psychiatry treatment can reduce both the length of hospitalization of psychiatric patients and the staggering costs of their hospitalization, which, along with a decrease of approximately 17 percent in the frequency of adhesion due to the implementation of CRP in the experimental group compared to the control group (although was not statistically significant), is worth noting and emphasizes the need to complement medication with non-pharmacological therapeutic approaches such as CRP.

\section{Conclusion}

In the study, the implementation of CRP in combination with conventional psychiatric treatment was able to have a significant effect on the therapeutic variables, all of which are among the problems faced by therapists in the treatment of severe psychiatric disorders, and its effect on two variables of hospitalization duration and adhesion frequency, although was not significant; but considering the whole findings of the study and the changes that occurred in other therapeutic variables, is noteworthy and due to the novelty of the study area should be examined in more details in future research. The results of the study emphasize that the CRP is a good method to improve social functioning and to a large extent can facilitate the treatment of patients in the acute phase of the disease and during hospitalization period and help improve the treatment outcome. The program enables patients to play a more active role in their treatment process and achieve more and more sustainable treatment accomplishments in a shorter period of time, a feature that, in addition to reducing treatment costs, has very beneficial effects on improving the treatment process.

\section{Abbreviations}

CRP: Community Re-entry program

Page $16 / 20$ 
UCLA: University of California, Los Angeles

PRN (Pro Re Nata): Intravenous or intramuscular injection of psychotropic drugs as ordered by the treating psychiatrist to calm the patient and immediately eliminate the risk in psychiatric emergency situations.

PANSS: Positive and Negative Syndrome Scale

\section{Declarations}

\section{Ethical approval}

All procedures performed in the study involving human participants were in accordance with the ethical standards of the research committee and committee of clinical ethics of University of Social Welfare and Rehabilitation Sciences, Tehran, Iran and conducted after receiving the code of ethics: IR.USWR.REC.1396.150.

\section{Informed consent}

Was obtained for all participants.

\section{Competing interests}

The authors declare that they had no competing interests.

\section{Authors' contributions}

Study design: DAGH. Data synthesis: DAGH, FS, AB and AD. Drafting the manuscript: AA, FKD and MKH. Critical revision of the manuscript: $D A G H, A B$ and $O R$. Final revision of manuscript: DAGH

\section{Consent for publication}

Yes

\section{Availability of data and materials}

Not applicable

\section{Funding}

The research was funded by University of Social Welfare and Rehabilitation Sciences (USWR)

\section{Acknowledgments}

The present study was carried out with coordination of Raazi Psychiatric Hospital, Research Deputy, and in collaboration with the Psychosis Research Center. The researchers express their gratitude and appreciation to all individuals and legal entities and patients of Raazi Psychiatric Hospital who sincerely cooperated in conducting this research.

\section{References}


1. Abbasi, A.; Aghaei Jeshvaghani, A.; \& Ebrahimi moghasam, H. (2019). Effectiveness of metacognitive therapy on resiliency in the people with generalized anxiety. Journal of psychologicalscience, 18 (78), 691-698.

2. Abbasi, A.; Aghaei Jeshvaghani, A.; \& Ebrahimi moghasam, H. (2020). Effectiveness of Metacognition Therapy on the Anxiety and Psychological Wellbeing of the Patients with Generalized Anxiety. medical journal of mashhad university of medical sciences, 63(4), -. doi: 10.22038/mjms.2021.17348

3. American Psychiatric Association. (2013). Diagnostic and Statistical Manual of Mental Disorders. $5^{\text {th }}$. ed. Arlington, VA: American Psychiatric Association.

4. American Psychiatric Association. (2020). The American Psychiatric Association Practice Guideline for the Treatment of Patients with Schizophrenia. American Psychiatric Pub

5. Anzai, N.; Yoneda, S.; Kumagai, N.; Nakamura, Y.; Ikebuchi, E.; \& Liberman, R. P. (2002). Training Persons with Schizophrenia in Illness Self-management: A Randomized Controlled Trial in Japan. Psychiatric Services, 53(5), 545-547. https://doi.org/10.1176/appi.ps.53.5.545

6. Arab Ghahestany, D., Sohrabi, F., Borjali, A., Delavar, A., \& Rezaei, O. (2018). A Qualitative Study on Attitude Toward Hospitalization in Schizophrenics and the CRP Effectiveness on It: An Interpretative Phenomenological Analysis. Iranian Journal of Rehabilitation Research in Nursing. 4 (4):59-71

7. Armijo, J.; Mendez, E.; Morales, R.; Schilling, S.; Castro, A.; Alvarado, R.; \& Rojas, G. (2013). Efficacy of Community Treatments for Schizophrenia and Other Psychiatric Disorders: A Literature Review. Front Psychiatry, 4, 116. https://doi.org/10.3389/fpsyt.2013.00116

8. Barlow, D. H., \& Durand, V. M. (2015). Abnormal Psychology: An Integrative Approach. $7^{\text {th }}$ ed. Stanford: Cengage Learning.

9. Bustillo, J. R.; Lauriello, J.; Horan, W. P.; \& Keith, S. J. (2001). The Psychosocial Treatment of Schizophrenia: An Update. American Journal of Psychiatry, 158, 163-175. https://doi.org/10.1176/appi.ajp.158.2.163

10. Gale. (2008). Encyclopedia of Medicine. Retrieved January 42017 from http://medical-dictionary. thefreedictionary .com/ negative+Syndrome.

11. Granholm, E.; McQuaid, J. R.; McClure, F. S.; Auslander, L. A.; Perivoliotis, D.; Pedrelli, P.; Patterson, T.; \& Jeste, D. V. (2005). A Randomized, Controlled Trial of Cognitive Behavioral Social Skills Training for Middle-aged and Older Outpatients with Chronic Schizophrenia. American Journal of Psychiatry, 162 (3): 520-529. https://doi.org/10.1176/appi.ajp.162.3.520.

12. Griffiths, S. L.; Wood, S. J.; Fowler, D.; Freemantle, N.; Hodgekins, J.; \& Jones, P. B. (2021). Improved Social Functioning following Social Recovery Therapy in First Episode Psychosis: Do Social Cognition and Neurocognition Change Following Therapy, and Do They Predict Treatment Response?. Schizophrenia Research, 228, 249-255. https://doi.org/10.1016/j.schres.2020.12.023

13. Gustavsson, A.; Svensson, M.; Jacobi, F.; Allgulander, C.; Alonso, J.; \& Beghi, E. (2011). Cost of Disorders of the Brain in Europe 2010. Eur. Neuropsychopharmacol. 21, 718-779. doi: 10.1016/j.euroneuro.2011.08.008.

14. Haghbin, H., Mohammadi, MR., Ahmadi, N., Khaleghi, A., Golmakani, H., Kaviyani, K., et al (2018). Prevalence of Psychiatric Disorders in Children and Adolescents of North Khorasan Province, Iran. North Khorasan Journal of Medical Sciences; 10,(1). 117- 127.

15. Jamshidia , F., Tohidi, S., Shayan, A. (2017). Effect of CRP on the Mental State in Chronic Mental IIInesses Daily Rehabilitation Centers in Hamadan. The Scientific Journal of Rehabilitation Medicine, 6(3), 60-67.

16. Jamshidi ${ }^{\text {}}$, F., Tohidi, S., Shayan, A. (2017). Comparison of the Effect of CRP (CRP) and Conventional Psychotherapy Programs on Syndromes Severity and Communication and Interaction skills of Persons With 
Severe Mental Disorders. IJRN. 3 (4) :21-28.

17. Kay, S. R. (1991). Positive and negative Syndromess in schizophrenia: assessment and research (Vol. 5). Psychology Press.

18. Khorrami, M.; Atashpour, S. H.; Arefi, M. (2019). Analyzing the Path Between Positive Psychological Functions among Mothers of Children with Cerebral Palsy. J North Khorasan Univ Med Sci. 10 (4): 28 -39. http://eprints.nkums.ac.ir/1776/

19. Liberman, R. P.; \& Silbert, K. (2005). Community Re-entry: Development of Life Skills. Psychiatry. 68 (3): $220-9$. doi: 10.1521/psyc.2005.68.3.220 PMID: 16253108

20. Liberman, R. P.; Wallace, C. j.; Blackwell, G.; Eckman, T. A.; Vaccaro, J. V.; and Knebnel, T. G. (1994). The UCLA Social and Independent Living Skills Modules. Innov. Res, 2, 43-59.

21. Liberman, R. P.; Wallace C. J.; Blackwell, G.; Kopelowicz, A.; Vaccaro J. V.; Mintz, J. (1998). Skills training versus psychosocial occupational therapy for persons with persistent schizophrenia. Am J Psychiatry.155 (8):108791. doi: 10.1176/ajp.155.8.1087 PMID: 9699698

22. Mohammadzadeh nanehkaran, S., Karbalaie Noori, A., Hosseini, S. A. (2013). Effect of CRP (CRM) in Patients with Schizophrenia. jrehab. 14 (2) :22-28.

23. Murphy, T. K.; Haigh, S. M.; Coffman, B. A.; \& Salisbury, D. F. (2020). Mismatch negativity and impaired social functioning in long-term and in first episode schizophrenia spectrum psychosis. Frontiers in Psychiatry, 11, 544. https://doi.org/10.3389/fpsyt.2020.00544

24. Noroozi, M.; Alibeigi, N.; Armoon, B.; Rezaei, O.; Sayadnasiri, M.; Nejati, S.; Fadaei, F.; Arab Ghahestany, D.; Dieji, B.; \& Ahounbar, E. (2018). Patterns of Relapse Risks and Related Factors among Patients with Schizophrenia in Razi Hospital, Iran: ALatent Class Analysis. Polish Psychological Bulletin. 49 (3): 355-359.

25. Okanli, A.; Karakas, S. A.; Altun, O. S.; and Selvi, Y. (2017). The Effect of the Social and Independent Living Skills, the CRP Application for Patients with Schizophrenia on their Functional Remission and Drug Adherence. Studies on Ethno-Medicine, 11(3), 233-238. https://doi.org/10.1080/09735070.2017.1305229

26. Sadock, B. J.; Sadock, V. A.; \& Ruiz, P. (2017). Kaplan and Sadock's Comprehensive Textbook of Psychiatry, $10^{\text {th }}$ ed. Vol. 4. New York: Wolters Kluwer.

27. Sadock, B. J.; Sadock, V. A.; and Ruiz, P. (2015). Kaplan and Sadock's Synopsis of Psychiatry, $11^{\text {th }}$ ed. Vol. 1. New York: Wolters Kluwer.

28. Sato, S.; Ikebuchi, E.; Anzai, N.; and Inoue, S. (2012). Effects of Psychosocial Program for Preparing Long-term Hospitalized Patients with Schizophrenia for Discharge from Hospital: Randomized Control Trials. Psychiatry and Clinical Neurosciences, 66, 474-481. https://doi.org/10.1111/j.1440-1819.2012.02393.x

29. Shrivastava, A.; \& Sousa, A. D. (2020). Schizophrenia treat- ment outcomes: An evidence-based approach to recovery. Springer International Publishing. https://doi.org/10.1007/978-3-030-19847-3.

30. Sue, D.; Sue, D. W.; and Sue, S. (2006). Understanding Abnormal Behavior. $8^{\text {th }}$ ed. Boston: Houghton Mifflin.

31. Wang, W.; Mirjafari, S.; Harari, G.; Ben-Zeev, D.; Brian, R.; Choudhury, T.; et al. (2020). Social sensing: assessing social functioning of patients living with schizophrenia using mobile phone sensing. In Proceedings of the 2020 CHI Conference on Human Factors in Computing Systems. 1-15.

https://doi.org/10.1145/3313831.3376855

32. Whiteford, H. A.; Degenhardt, L.; Rehm, J.; Baxter, A. J.; Ferrari, A. J.; Erskine, H. E.; et al. (2013). Global burden of disease attributable to mental and substance use disorders: findings from the Global Burden of Disease Study. Lancet 382, 1575-1586. doi: 10.1016/S0140-6736(13)61611-6. 
33. Xiang, Y.; Weng, Y.; Li, W.; Gao, L.; Chen, G.; Xie, L.; Chang, Y.; Tang, W.; and Ungvari, G. S. (2006). Training Patients with Schizophrenia with the Community Re-entry module. Social Psychiatry and Psychiatric Epidemiology, 41(6), 464-469. doi: 10.1007/s00127-006-0050-6

34. Xiang, Y.; Weng, Y.; Li, W.; Gao, L.; Chen, G.; Xie, L.; Chang, Y.; Tang, W.; and Ungvari, G. S. (2007). Efficacy of The Community Re-entry Module for Patients with Schizophrenia in Beijing, China: Outcome at 2-year Follow-up. British Journal of Psychiatry, 190, 49-56. doi: https://doi.org/10.1192/bjp.bp.106.023697 